\title{
Atomic Layer Deposition to Fine-Tune the Surface Properties and Diameters of Fabricated Nanopores
}

\section{Citation}

Chen, Peng, Toshiyuki Mitsui, Damon B. Farmer, Jene Golovchenko, Roy G. Gordon, and Daniel Branton. 2004. Atomic layer deposition to fine-tune the surface properties and diameters of fabricated nanopores. Nano Letters 4(7): 1333-1337.

\section{Published Version}

http://dx.doi.org/10.1021/nl0494001

\section{Permanent link}

http://nrs.harvard.edu/urn-3:HUL.InstRepos:3109363

\section{Terms of Use}

This article was downloaded from Harvard University's DASH repository, and is made available under the terms and conditions applicable to Other Posted Material, as set forth at http:// nrs.harvard.edu/urn-3:HUL.InstRepos:dash.current.terms-of-use\#LAA

\section{Share Your Story}

The Harvard community has made this article openly available.

Please share how this access benefits you. Submit a story.

\section{Accessibility}




\title{
Atomic Layer Deposition to Fine-Tune the Surface Properties and Diameters of Fabricated Nanopores
}

\author{
Peng Chen, ${ }^{\dagger}$ Toshiyuki Mitsui, $¥$ Damon B. Farmer, $§$ Jene Golovchenko,,$\S$ \\ Roy G. Gordon," and Daniel Branton ${ }^{\star}, \dagger$

\begin{abstract}
Department of Molecular and Cellular Biology, Department of Physics, Division of Engineering \& Applied Sciences, and Department of Chemistry \& Chemical Biology, Harvard University, Cambridge, Massachusetts 02138
\end{abstract}

Received April 23, 2004; Revised Manuscript Received May 12, 2004

\begin{abstract}
Atomic layer deposition of alumina enhanced the molecule sensing characteristics of fabricated nanopores by fine-tuning their surface properties, reducing $1 / \mathrm{f}$ noise, neutralizing surface charge to favor capture of DNA and other negative polyelectrolytes, and controlling the diameter and aspect ratio of the pores with near single Angstrom precision. The control over the chemical and physical nature of the pore surface provided by atomic layer deposition produced a higher yield of functional nanopore detectors.
\end{abstract}

Nanopore sensors, whose ionic conductivity can be diminished by the passage of target molecules, can transduce the passage of a single macromolecule into a discrete electrical signal whose characteristics reveal some of the translocating molecule's properties. ${ }^{1-4}$ But despite the stability, tunability, and other potential advantages that fabricated solid state nanopores may offer, the ion beam, electron beam, or chemical etch fabrication conditions used to create nanopores usually yield uncharacterized and possibly unfavorable surface properties that can interfere with the pore's sensing abilities.

Nanopores are often created in an insulating membrane. ${ }^{2-4}$ Ion beam sculpting employing feedback control has been used to fabricate such nanopores in thin silicon nitride membranes. $^{2}$ To respond to single molecules in a high throughput, selective, and sensitive manner, the properties of both the membrane and the nanopore must be carefully selected. For example, the surface properties of the pore and its immediate surroundings should not repel the molecules that are to be detected, and the limiting aperture of the pore must have a diameter large enough to allow the molecules to translocate, but small enough to optimize signal response to the molecules' presence. While it is evident that both the membrane surface properties and the nanopore dimensions are critical, there have been impediments to achieving simultaneous control of both surface properties and nanopore

\footnotetext{
* Corresponding author. Telephone: 617-495-2646; Fax: 617-384-7732 e-mail: dbranton@harvard.edu.

$\dagger$ Department of Molecular and Cellular Biology.

$\doteqdot$ Department of Physics.

$\S$ Division of Engineering \& Applied Sciences.

"Department of Chemistry \& Chemical Biology.
}

size because the choice of membrane material is usually limited by the technical features of the fabrication processes. The surface chemistry of the chosen membrane may not be ideal for the application of interest. Furthermore, the best fabrication methods that have been used to control final pore size, such as counting transmitted $\mathrm{Ar}^{+}$ions ${ }^{2}$ or direct visualization in an electron beam, ${ }^{3}$ inevitably produce variable modifications of the membrane's surface charge or other characteristics. The resulting surface may make the pore unfavorable or inhibitory to probing molecules and may produce electrical noise that degrades the desired signal. ${ }^{5}$ Here, we show that atomic layer deposition $(A L D)^{6,7}$ of a highly conformal thin film of $\mathrm{Al}_{2} \mathrm{O}_{3}$ can provide a finishing step to fine-tune both the surface properties and the sizes of fabricated nanopores.

As previously shown, when DNA was driven through such a nanopore by a voltage bias, temporary blockages of the ion current signals revealed the presence and characteristic features of a translocating molecule. ${ }^{8}$ But disappointingly, reasonably high throughput DNA translocation ( $>1$ molecule/ $10 \mathrm{~s}$ from a solution containing $5 \mu \mathrm{g} / \mathrm{mL}$ of $\lambda$-DNA with a $200 \mathrm{mV}$ bias) was observed in only a small percentage of our fabricated nanopores. We reasoned that this irreproducible, but generally low-throughput behavior might be due to variability in the ion selective properties of the nanopore which could, in many cases, be rejecting the polyanionic DNA.

To test this hypothesis, we determined the ion selectivity of our nanopores to assess their anion or cation permeability. The predominant current carriers in our buffer solution were 


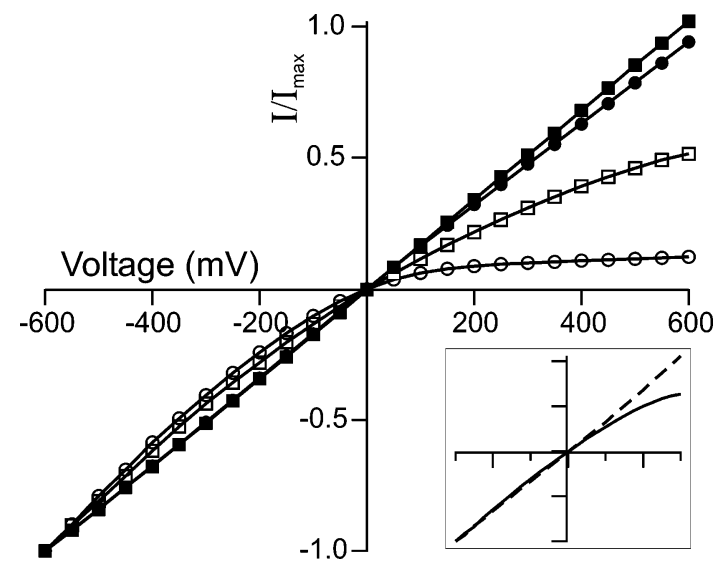

Figure 1. $I-V$ curves of ion-sculpted nanopores (both with diameters $\sim 14 \mathrm{~nm}$ ) in $1 \mathrm{M} \mathrm{KCl}$ at $\mathrm{pH} 8.0$ (circles) and at $\mathrm{pH} 2.0$ (squares), without (open circles and squares) and with (filled circles and squares) coating by ALD of $3 \mathrm{~nm}$ of $\mathrm{Al}_{2} \mathrm{O}_{3}$. The current is normalized to the maximum current $\left(I_{\max }\right)$ observed at $-600 \mathrm{mV}$. Only the uncoated nanopore (open symbols) exhibited rectification, strongly at $\mathrm{pH} 8.0$ (circles), less strongly at $\mathrm{pH} 2.0$ (squares). The uncoated pore's cation selectivity was $94.5 \%$ at $\mathrm{pH} 8.0$ and $80.1 \%$ at $\mathrm{pH} 2.0$; the coated pore's cation selectivity was $50.5 \%$ at $\mathrm{pH}$ 8.0, and $48.7 \%$ at $\mathrm{pH} 2.0$. Inset (axes as in main figure): $I-V$ curves of an ion-sculpted nanopore, at $\mathrm{pH} 8.0$ (solid line) and at $\mathrm{pH} 2.0$ (dashed line) but after overcoating $3 \mathrm{~nm} \mathrm{Al} \mathrm{O}_{2} \mathrm{O}_{3}$ with $3 \mathrm{~nm}$ silica (see Methods). Final pore diameter, $\sim 17 \mathrm{~nm}$. Cation selectivity $\sim 57.5 \%$ at $\mathrm{pH} 8 ; 49.0 \%$ at $\mathrm{pH} 2.0$.

potassium and chloride ions. The permeability ratio $\left(P_{\mathrm{K}^{+}} /\right.$ $\left.P_{\mathrm{Cl}^{-}}\right)$, and hence the cation selectivity $P_{\mathrm{K}^{+}} /\left(P_{\mathrm{K}^{+}}+P_{\mathrm{Cl}^{-}}\right)$, was calculated from reversal potential measurement using the Goldman-Hodgkin-Katz (GHK) equation ${ }^{9}$

$$
\frac{P_{\mathrm{K}^{+}}}{P_{\mathrm{Cl}^{-}}}=\frac{\left[a_{\mathrm{Cl}^{-}}\right]_{t}-\left[a_{\mathrm{Cl}^{-}}\right]_{c} e^{V_{\mathrm{rev}} F / R T}}{\left[a_{\mathrm{K}^{+}}\right]_{t} e^{V_{\mathrm{rev}} F / R T}-\left[a_{\mathrm{K}+}\right]_{c}}
$$

where $V_{\text {rev }}$ is the reversal potential, $a_{\mathrm{X}}$ is the activity of ion $\mathrm{X}$, subscripts $c$ and $t$ refer to the cis and trans chambers, and other symbols have their usual meanings. The reversal potential, $V_{\text {rev }}$, was determined by subtracting the zero-current electrical potential under symmetric conditions $(1 \mathrm{M} \mathrm{KCl}$ on both sides of the nanopore) from that under asymmetric conditions $(0.2 \mathrm{M} \mathrm{KCl}$ on the cis side of the nanopore, 1.0 $\mathrm{M} \mathrm{KCl}$ on the trans side). At $\mathrm{pH} 8.0$ (the $\mathrm{pH}$ used for our standard DNA translocation experiments $), P_{\mathrm{K}^{+}} /\left(P_{\mathrm{K}^{+}}+P_{\mathrm{Cl}^{-}}\right)$ $=71 \pm 10.3 \%$ for 10 ion sculpted nanopores (all $\sim 13 \pm 2$ $\mathrm{nm}$ in diameter). This clear cation selectivity and large nanopore-to-nanopore variability $( \pm 10.3 \%)$ were consistent with our observation that only a few of our nanopores allowed high throughput translocation of the anionic DNA polymers.

The current vs voltage plots ( $I-V$ plots) of many ion beam sculpted nanopores were nonlinear, i.e., their conductance was rectified. Rectification and selectivity altered in concert, and both were modulated by $\mathrm{pH}$ (Figure 1). In low $\mathrm{pH}$ conditions, where negatively charged surface sites were likely to have been protonated, the pores exhibited less rectification and less selectivity. Similar phenomena have been noted in track-etched nanopores in poly(ethylene terephthalate), 5,10 glass pipets with tapering small tips $(20-100 \mathrm{~nm}),{ }^{11,12}$ and biological channels. ${ }^{13,14}$ Uneven electrostatic field effects from inhomogeneous surface charge distribution or asymmetric geometry are believed to be responsible for current rectification. ${ }^{9}$

Together, all of these observations led us to conclude that the variable cation selectivity we measured was due to variable surface charge. To enter a negatively charged pore, DNA molecules would have to overcome not only electrostatic repulsion but also any electroosmotic flow caused by the negatively charged sidewalls of our nanopore. Such electroosmotic flow would oppose the electrophoretic force driving the DNA through the nanopore.

A further difficulty we noted when measuring the electrical properties of a large proportion of our nanopores was dominant low frequency conductance fluctuations whose powers decreased linearly with increasing frequency (Figure 2a). Such noise is observed in many biological and physical systems and is commonly referred to as $1 / f$ noise..$^{15,16}$ This noise, of unidentified origin, made it difficult or impossible to detect the current blockages due to true DNA translocation. The spectral density of the $1 / f$ noise was proportional to the square of the applied voltage bias across the nanopore (Figure 2b), as expected from Hooge's model. ${ }^{16}$ Although there was no apparent correlation between the $1 / f$ noise level and the cation selectivity of the nanopore, the fact that $1 / f$ noise has been attributed to charge fluctuations in other systems ${ }^{17-19}$ reinforced our misgivings about the unknown and possibly variable state of our nanopore surface. Our nanopores had been fabricated by the interactions of a $\mathrm{Si}_{3} \mathrm{~N}_{4}$ membrane with an unknown number of $\mathrm{Ga}^{+}$ions during FIB drilling, an unknown number of $\mathrm{Ar}^{+}$ions during ion beam sculpting, and, for pores verified by TEM imaging, an uncertain exposure to an electron beam.

We reasoned that atomic layer deposition (ALD) from a chemical vapor could be an ideal method to coat the entirety of our nanopore surfaces with a homogeneous film of known composition. ALD can yield highly conformal step coverage of many different materials, even over high-aspect-ratio structures (aspect ratios $>100$ ) with precise thickness control. $^{7,20}$ Aluminum oxide was chosen as our coating material because it has a nominal isoelectric point at $\sim \mathrm{pH}$ $9.0^{21}$ and should therefore not present a negatively charged surface that repels anionic DNA at pH 8.0. $\mathrm{Al}_{2} \mathrm{O}_{3}$ is a thermally and chemically stable insulating dielectric material that inhibits direct electron tunneling and exhibits negligible ion diffusion. Indeed, in contrast to the uncoated nanopores at $\mathrm{pH}$ 8.0, the $\mathrm{ALD}-\mathrm{Al}_{2} \mathrm{O}_{3}$ coated pores were not ion selective $\left(P_{\mathrm{K}^{+}} /\left[P_{\mathrm{K}^{+}}+P_{\mathrm{Cl}^{-}}\right]=51.4 \pm 1.3 \%\right.$ for 10 ion sculpted ALD$\mathrm{Al}_{2} \mathrm{O}_{3}$ coated nanopores, all $\sim 13 \pm 2 \mathrm{~nm}$ in diameter after $3 \mathrm{~nm}$ alumina coating) and, as expected from the absence of ion selectivity, these $\mathrm{ALD}-\mathrm{Al}_{2} \mathrm{O}_{3}$ coated nanopores were not rectifying (Figure 1). As anticipated given the lack of ion selectivity, high throughput DNA translocation was observed in all of our ALD- $\mathrm{Al}_{2} \mathrm{O}_{3}$ pores and, in addition, $1 / f$ noise was gratifyingly insignificant at all voltage levels, ensuring sufficient signal-to-noise ratio for detecting DNA translocation (Figure 3). 

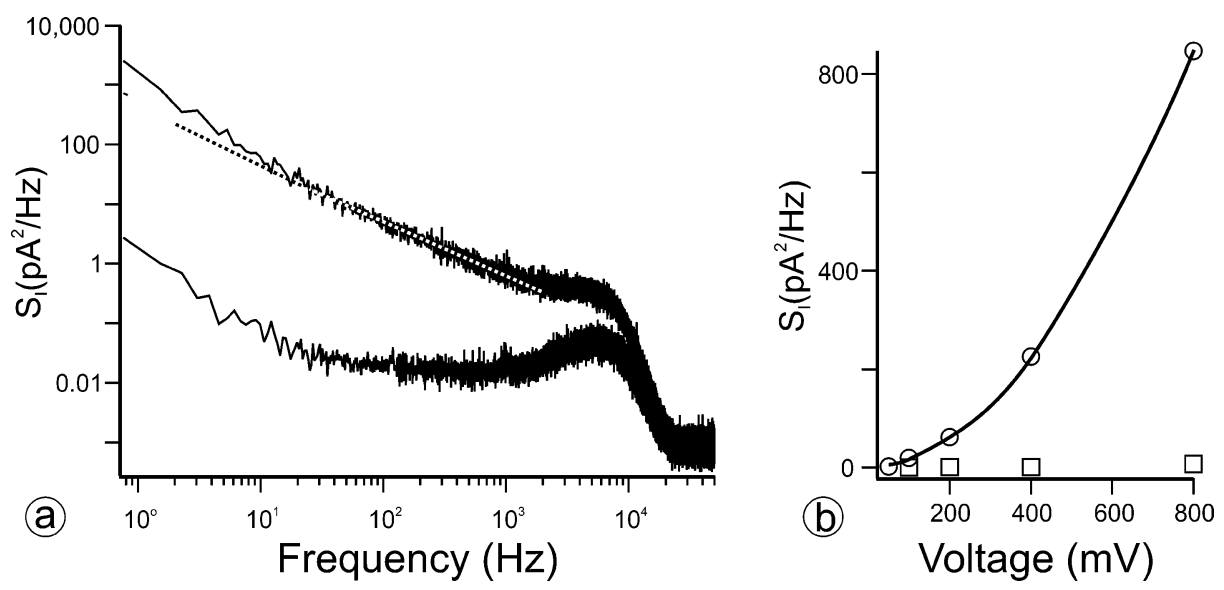

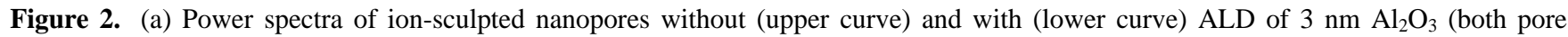
diameters $\sim 10 \mathrm{~nm}$ ). Both measurements in buffered $1 \mathrm{M} \mathrm{KCl}, \mathrm{pH} 8.0$, at $200 \mathrm{mV}$. Note the 1/f fitting (dotted line). (b) Noise level (at 10 $\mathrm{Hz}$ where $1 / f$ noise dominates) increases with applied voltage level for the nanopore without coating (circles). The data are fitted by $S_{\mathrm{I}}=$ $A_{0} *$ Voltage ${ }^{1.92}$ (curve). On the other hand, $1 / f$ noise is not significant at all voltage levels for the ALD nanopore (squares).
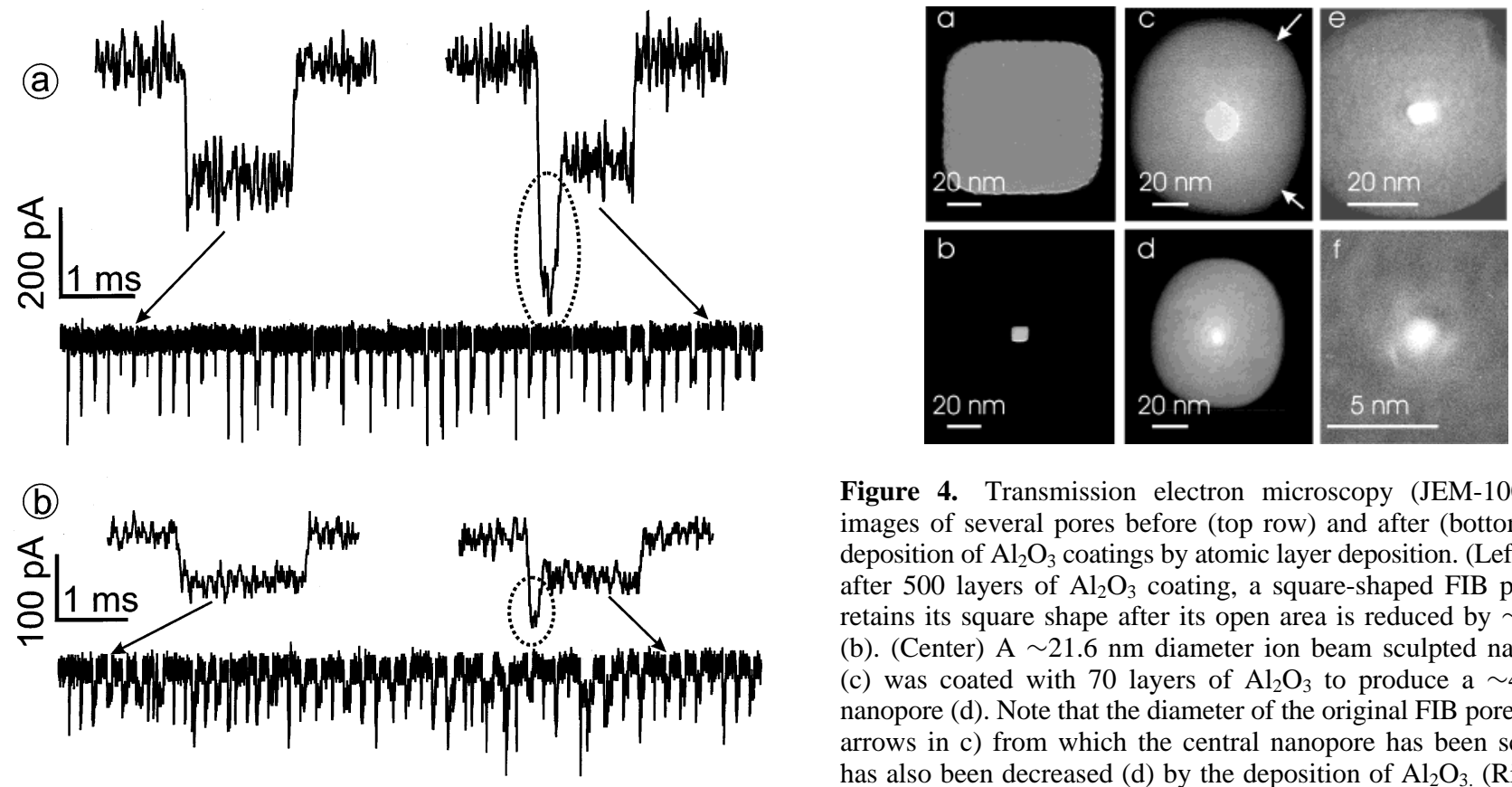

Figure 4. Transmission electron microscopy (JEM-100CXII) images of several pores before (top row) and after (bottom row) deposition of $\mathrm{Al}_{2} \mathrm{O}_{3}$ coatings by atomic layer deposition. (Left) Even after 500 layers of $\mathrm{Al}_{2} \mathrm{O}_{3}$ coating, a square-shaped FIB pore (a) retains its square shape after its open area is reduced by $\sim 9$-fold (b). (Center) $\mathrm{A} \sim 21.6 \mathrm{~nm}$ diameter ion beam sculpted nanopore (c) was coated with 70 layers of $\mathrm{Al}_{2} \mathrm{O}_{3}$ to produce a $\sim 4.8 \mathrm{~nm}$ nanopore (d). Note that the diameter of the original FIB pore (white arrows in c) from which the central nanopore has been sculpted has also been decreased (d) by the deposition of $\mathrm{Al}_{2} \mathrm{O}_{3}$. (Right) $\mathrm{A}$ $\sim 7.1 \mathrm{~nm}$ diameter ion beam sculpted nanopore (e) was coated with 24 layers of $\mathrm{Al}_{2} \mathrm{O}_{3}$ to produce a $\sim 2.0 \mathrm{~nm}$ nanopore (f).

Figure 3. Translocation of bacteriophage lambda DNA (48.5 kbp)

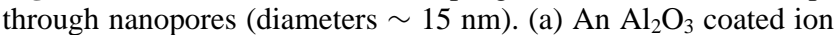
beam sculpted nanopore: final diameter $\sim 15 \mathrm{~nm}$, length $\sim 40 \mathrm{~nm}$. Each current blockage event represents a single DNA molecule passing through the pore. Two such events are enlarged from the several-second recording (arrows) and displayed in large scale. (b) An $\mathrm{Al}_{2} \mathrm{O}_{3}$ coated FIB pore: final diameter $\sim 15 \mathrm{~nm}$, length $\sim 250$ $\mathrm{nm}$. The DNA translocates in similar time duration but causes smaller current blockage because of greater pore length of the FIBcoated pore. The enhanced portion of some blockages (within the dashed elipses) reflects a portion of the translocating DNA molecule that is folded on itself, such that two strands of the double-helix occupy the nanopore simultaneously. ${ }^{8}$ Translocation was driven by a $300 \mathrm{mV}$ voltage bias.

To determine if the absence of pore rectification after ALD- $\mathrm{Al}_{2} \mathrm{O}_{3}$ coating was truly correlated with the observed absence of surface charge and selectivity, or simply a coincidental consequence of ALD treatment, several ALD$\mathrm{Al}_{2} \mathrm{O}_{3}$ coated nanopores were overcoated with silica by ALD treatment. ${ }^{22}$ Since silica is known to be negatively charged

at $\mathrm{pH} 8.0$ and lose this charge only at $\mathrm{pH}<3,{ }^{21}$ these pores exhibited cation selectivity $\left(P_{\mathrm{K}^{+}} /\left[P_{\mathrm{K}^{+}}+P_{\mathrm{Cl}^{-}}\right]\right.$averaged $60 \%$ for three $\sim 18 \mathrm{~nm}$ diameter pores), and this selectivity was indeed correlated with the reappearance of $\mathrm{pH}$-sensitive rectification (Figure 1, inset).

As already demonstrated in other applications, ${ }^{7,20}$ ALD from the vapor phase proved itself to be highly conformal: a square FIB-drilled pore in $\mathrm{Si}_{3} \mathrm{~N}_{4}$ maintained its square contours even after 500 cycles of $\mathrm{Al}_{2} \mathrm{O}_{3}$ deposition (Figure $4 \mathrm{a}, \mathrm{b})$. Because ALD can incrementally and uniformly add material to all exposed surfaces, including the side walls lining the diameter of a nanopore, it is an atomically precise method of creating a nanopore, shrinking an oversized pore to a preferred smaller diameter (Figure $4 \mathrm{c}-\mathrm{f}$ ). We found that under our conditions (see Methods) the deposition rate of $\mathrm{Al}_{2} \mathrm{O}_{3}$ was $0.099 \pm 0.012 \mathrm{~nm}(n=31)$ per reaction cycle, independent of the total number of cycles $(20-500$ cycles 
were used for this calibration). This deposition rate was in line with other measurements for deposition of metal oxides on silicon surfaces (e.g., $\mathrm{Al}_{2} \mathrm{O}_{3},{ }^{23} \mathrm{HfO}_{2}{ }^{20}$ ). In 14 independent trials on plain FIB-drilled nanopores and 17 trials on ion beam sculpted nanopores, we found that all of the pores had been closed down to their predicted size while still maintaining their initial shapes. Thus, starting with a $2 \mathrm{~nm}$ diameter ion beam sculpted nanopore, one can, in principle, reproducibly adjust its diameter to $1 \mathrm{~nm}$ by 5 cycles of $\mathrm{Al}_{2} \mathrm{O}_{3}$ layer deposition with an error of only $\sim \pm 0.12 \mathrm{~nm}$. Furthermore, although our unoptimized error rate for $\mathrm{Al}_{2} \mathrm{O}_{3}$ ALD on $\mathrm{Si}_{3} \mathrm{~N}_{4}$ was $\pm 12 \%$, improvements should yield error rates commensurate with the $\pm 2 \%$ achieved for $\mathrm{HfO}_{2}$ and $\mathrm{ZrO}_{2}$ on silicon substrate. ${ }^{20}$ But however precise the deposition rate, it is important to realize that, because deposition by ALD occurs on all exposed surfaces, the length of a nominally cylindrical $2 \mathrm{~nm}$ diameter pore through a $5 \mathrm{~nm}$ thick membrane would be increased from $5 \mathrm{~nm}$ to $\sim 6 \mathrm{~nm}$ as the pore diameter was decreased from 2 to $1 \mathrm{~nm}$. Such increases in the length of the pore may be desirable or undesirable, depending on the particular application. Both "short" and "long" nanopores detect single DNA molecules as an ionic current blockage during translocation of a polymer (Figure 3), but, as expected from simple Ohm's law considerations, the blockages in a short nanopore were greater than the current blockages during translocation of a polymer through a longer nanopore of similar diameter (compare Figure $3 \mathrm{~A}$ and $3 \mathrm{~B}$ ). Ion beam sculpting alone usually produces nanopores that are $\sim 5-40 \mathrm{~nm}$ long, depending on the pore size and the ion beam sculpting conditions.

Our results demonstrate a strategy of using atomic layer deposition to improve or create a single-molecule sensor by precisely adjusting a pore's diameter while simultaneously modifying the product's critical surface properties in a well controlled manner. Starting with large pores of any shape, correspondingly shaped single-nanometer sized, high aspect ratio channels can be produced by ALD. Alternatively, starting with an already small ion beam sculpted nanopore of known diameter in a thin membrane, a short, molecularly sized nanopore can be fashioned with atomic precision without the need for final TEM verification. Our results show that an $\mathrm{Al}_{2} \mathrm{O}_{3}$ deposited film can passivate a nonideal surface to eliminate unwanted selectivity, decrease $1 / f$ noise, and serve as a protective coating because of its hardness and stability. Using ALD techniques, other dielectrics can be utilized to fine-tune nanopore size while simultaneously producing homogeneous surfaces with a range of different charges and other properties ${ }^{6,21}$ to meet the requirements of many different applications.

Methods. Nanopore Fabrication. Nanopores were fabricated as described ${ }^{2}$ in $25 \mu \mathrm{m} \times 25 \mu \mathrm{m}$, free-standing, stoichiometric, low-pressure chemical vapor deposited, 200 $\mathrm{nm}$ thick $\mathrm{Si}_{3} \mathrm{~N}_{4}$ membranes that were supported on a $12 \mathrm{~mm}$ $\times 6 \mathrm{~mm} \times 0.4 \mathrm{~mm}$ N-type, phosphorus-doped, silicon substrate (100) frame. A 70-100 nm diameter pore was initially drilled at the center of this membrane using a focused ion beam machine (FIB, Micron 9500). This large pore was subsequently sculpted with feedback control using a 3-keV $\mathrm{Ar}^{+}$ion beam, during which process the pore size was continuously monitored by counting the $\mathrm{Ar}^{+}$flux through the pore. $\mathrm{The} \mathrm{Ar}^{+}$ion beam stimulated lateral atomic flow of $\mathrm{Si}_{3} \mathrm{~N}_{4}$ to create a thin film of $\mathrm{Si}_{3} \mathrm{~N}_{4}$ material that defines a nanopore at one end of the cylindrical FIB pore. The final product was a nanopore in a $\sim 5-40 \mathrm{~nm}$ thick film of $\mathrm{Si}_{3} \mathrm{~N}_{4}$ across one end of the $200 \mathrm{~nm}$-long FIB channel. ${ }^{2}$ In general, the pore thickness was proportional to the pore diameter. For example, the thickness, or length, of a $5 \mathrm{~nm}$ diameter pore was about $5 \mathrm{~nm}$.

$A L D$. Atomic layer deposition of $\mathrm{Al}_{2} \mathrm{O}_{3}$ was carried out in a homemade flow reactor at $225^{\circ} \mathrm{C}$ using electronically controlled valves as previously reported..$^{20}$ To generate reactive hydroxylated surfaces, all samples were treated by UV/ozone for $10 \mathrm{~min}$ immediately before placement in the flow reactor. Metal precursor, trimethylaluminum $\left[\mathrm{Al}\left(\mathrm{CH}_{3}\right)_{3}\right]$, was purchased from Aldrich Chemical Co. Water vapor was used as the oxygen source to form $\mathrm{Al}_{2} \mathrm{O}_{3}$. One $\mathrm{ALD}$ reaction cycle is defined as $1 \mathrm{~s}$ of $\mathrm{Al}\left(\mathrm{CH}_{3}\right)_{3}$ vapor flow into the reaction chamber followed by $5 \mathrm{~s}$ nitrogen purge, and then $1 \mathrm{~s}$ flow of water vapor followed by another $5 \mathrm{~s}$ nitrogen purge. Silica was deposited as a nanolaminate as described..$^{22}$

Nanopore Setup and Data Acquisition. The solution on top of the nanopore (cis side) was confined either by a small chamber made of poly(dimethylsiloxane) (PDMS) or a glass capillary tube equipped with a grounding $\mathrm{Ag} / \mathrm{AgCl}$ electrode. The circuit was completed by a positively biased $\mathrm{Ag} / \mathrm{AgCl}$ electrode in a PDMS chamber (trans side) underneath the nanopore chip. The $\mathrm{Ag} / \mathrm{AgCl}$ electrodes contacted the buffered $\mathrm{KCl}$ solutions surrounding and within the nanopore. The contact was through a $1 \mathrm{M} \mathrm{KCl}$ buffered agarose gel bridge. All experiments were performed at room temperature. The signals were acquired in an event-driven mode at a 10 $\mu$ s sampling rate and low-pass filtered at $10 \mathrm{kHz}$ using an Axopatch 200B.

Solutions and Reagents. The standard buffer solution contained $1 \mathrm{M}$ (or $0.2 \mathrm{M}$ ) KCl, $10 \mathrm{mM}$ Tris- $\mathrm{HCl}, 1 \mathrm{mM}$ EDTA, (pH 8.0). To record DNA translocation events, $5 \mu \mathrm{g} /$ $\mathrm{mL}$ bacteriophage $\lambda$ dsDNA (New England Biolabs) was added to the cis side of the nanopore. For experiments requiring $\mathrm{pH} 2.0$ solutions, the $10 \mathrm{mM}$ Tris was replaced by $10 \mathrm{mM}$ phosphate.

Acknowledgment. We thank Philippe de Rouffignac for performing the ALD of silica and Eric Brandin for providing the $\lambda$-DNA and able technical help throughout. D.B.F. was supported by NSF grant CTS-0236584 and the research was supported by NIH HG002338.

\section{References}

(1) Bayley, H.; Cremer, P. S. Nature 2001, 413, 226

(2) Li, J.; Stein, D.; McMullan, C.; Branton, D.; Aziz, M. J.; Golovchenko, J. A. Nature 2001, 412, 166.

(3) Storm, A. J.; Chen, J. H.; Ling, X. S.; Zandbergen, H. W.; Dekker, C. Nature Materials 2003, 2, 537.

(4) Siwy, Z.; Dobrev, D.; Neumann, R.; Trautmann, C.; Voss, K. O. Appl. Phys. A 2003, 76, 781.

(5) Lev, A. A.; Korchev, Y. E.; Rostovtseva, T. K.; Bashford, C. L.; Edmonds, D. T.; Pasternak, C. A. Proc. R. Soc. London B 1993 , 252,187 
(6) Jones, A. C.; Chalker, P. R. J. Phys. D: Appl. Phys. 2003, 36, R80.

(7) Gordon, R. G.; Hausmann, D.; Kim, E.; Shepard, J. Chem. Vap. Deposition 2003, 9, 73.

(8) Li, J.; Gershow, M.; Stein, D.; Brandin, E.; Golovchenko, J. Nature Materials 2003, 2, 611.

(9) Hille, B. Ion channels of excitable membranes, 3rd ed.; Sinauer Associates: Sunderland, MA, 2001.

(10) Siwy, Z.; Gu, Y.; Spohr, H. A.; Baur, D.; Wolf-Reber, A.; Spohr, R.; Apel, P. Y.; Korchev, Y. E. Europhys. Lett. 2002, 60, 349.

(11) Wei, C.; Bard, A. J. Anal. Chem. 1997, 69, 4627.

(12) Fahraeus, C.; Borglid, K.; Grampp, W. J. Neurosci. Methods 1997, $78,15$.

(13) Chen, D.; Lear, J.; Eisenberg, R. S. Biophys. J. 1997, 72, 97.

(14) Eismann, E.; Muller, F.; Heinemann, S. H.; Kaupp, U. B. Proc. Natl. Acad. Sci. U.S.A. 1994, 91, 1109.
(15) Verveen, A. A.; DeFelice, L. J. Prog. Biophys. Mol. Biol. 1974, 28, 189.

(16) Hooge, F. N. Physica 1972, 60, 130.

(17) Weissman, M. B. Rev. Mod. Phys. 1988, 60, 537.

(18) Dutta, P.; Horn, P. M. Rev. Mod. Phys. 1981, 53, 497.

(19) Bashford, C. L.; Alder, G. M.; Pasternak, C. A. Biophys. J. 2002, 82, 2032.

(20) Hausmann, D. M.; Kim, E.; Becker, J.; Gordon, R. G. Chem. Mater 2002, 14, 4350.

(21) Kosmulski, M. J. Colloid Interface Sci. 2002, 253, 77.

(22) Hausmann, D.; Becker, J.; Wang, S.; Gordon, R. G. Science 2002, 298,402

(23) Higashi, G. S.; Fleming, C. G. Appl. Phys. Lett. 1989, 55, 1963.

NL0494001 